\title{
Secondary Amenorrhea due to Abnormalities of the Autosomal Chromosomes- Case Report
}

\author{
Adriana Gogoi ${ }^{2}$, Ana Maria Hilma ${ }^{3,4}$, Oana Popa ${ }^{1}$, Camelia Procopiuc ${ }^{1}$ \\ "C.I.Parhon" National Institute of Endocrinology, Bucharest, Romania \\ "Medicover" Private Clinic, Bucharest, Romania \\ Elias University Emergency Hospital, Bucharest, Romania \\ Geviana Medica Company, Sibiu, Romania
}

Introduction: Follicle-stimulating hormone (FSH) and its corresponding receptor (FSHR) are essential factors for regular gonadal development, sexual maturation at puberty and gamete production during the fertile period in both sexes. The FSHR encoding gene was mapped to the short arm of chromosome (CR) 2 in 2p16.3.3 In females, inactivating mutations result clinically - depending on the degree of inactivation - in primary amenorrhea, secondary amenorrhea or premature ovarian failure (POF).

We present the case of a 17 y.o. girl who presented in our clinic with secondary amenorrhea. She had only one spontaneous menstrual bleeding at the age of 15 . She presented with spontaneous sexualisation corresponding to Tanner stage 5, had a normal neuropsychomotor development during childhood and didn't showed any dysmorphic signs. Bone age corresponded to the chronological age.

Laboratory investigations confirmed hypergonadotropic hypogonadism with prepubertal estradiol levels: $F S H$ 99.42 IU/I ( follicular phase 3.5-12.5 IU/l), LH $42.34 \mathrm{U} / \mathrm{l}$ ( follicular phase 2.4-12.6 IU/l), estradiol $21 \mathrm{pg} / \mathrm{ml}$ ( follicular phase $27-122 \mathrm{pg} / \mathrm{ml}$ ). Her prolactin and cortisol level, thyroid function, and beta HCG were in the normal range. Ovarian ultrasound didnt show any ovarian follicular development.

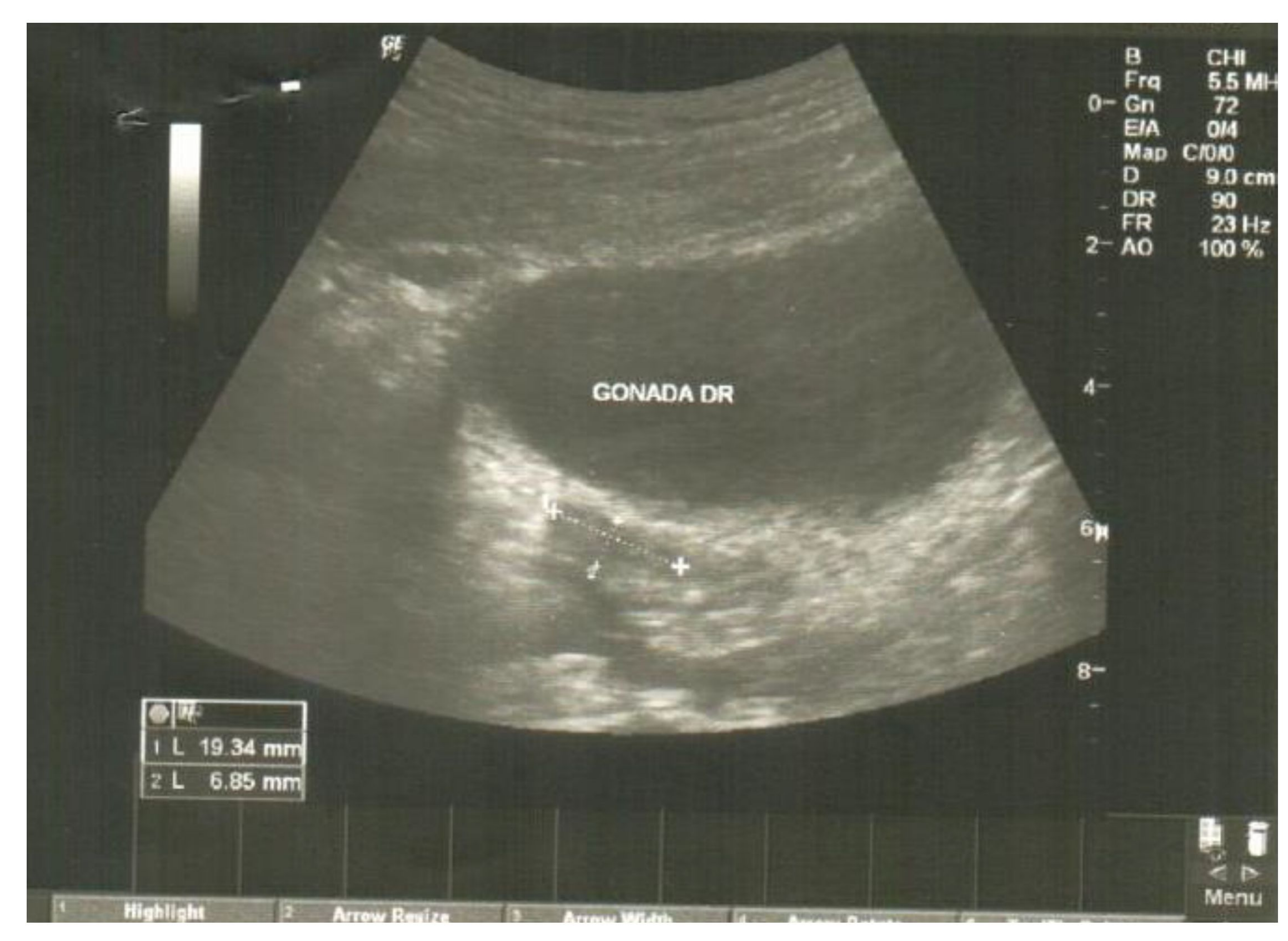

1.Right ovary

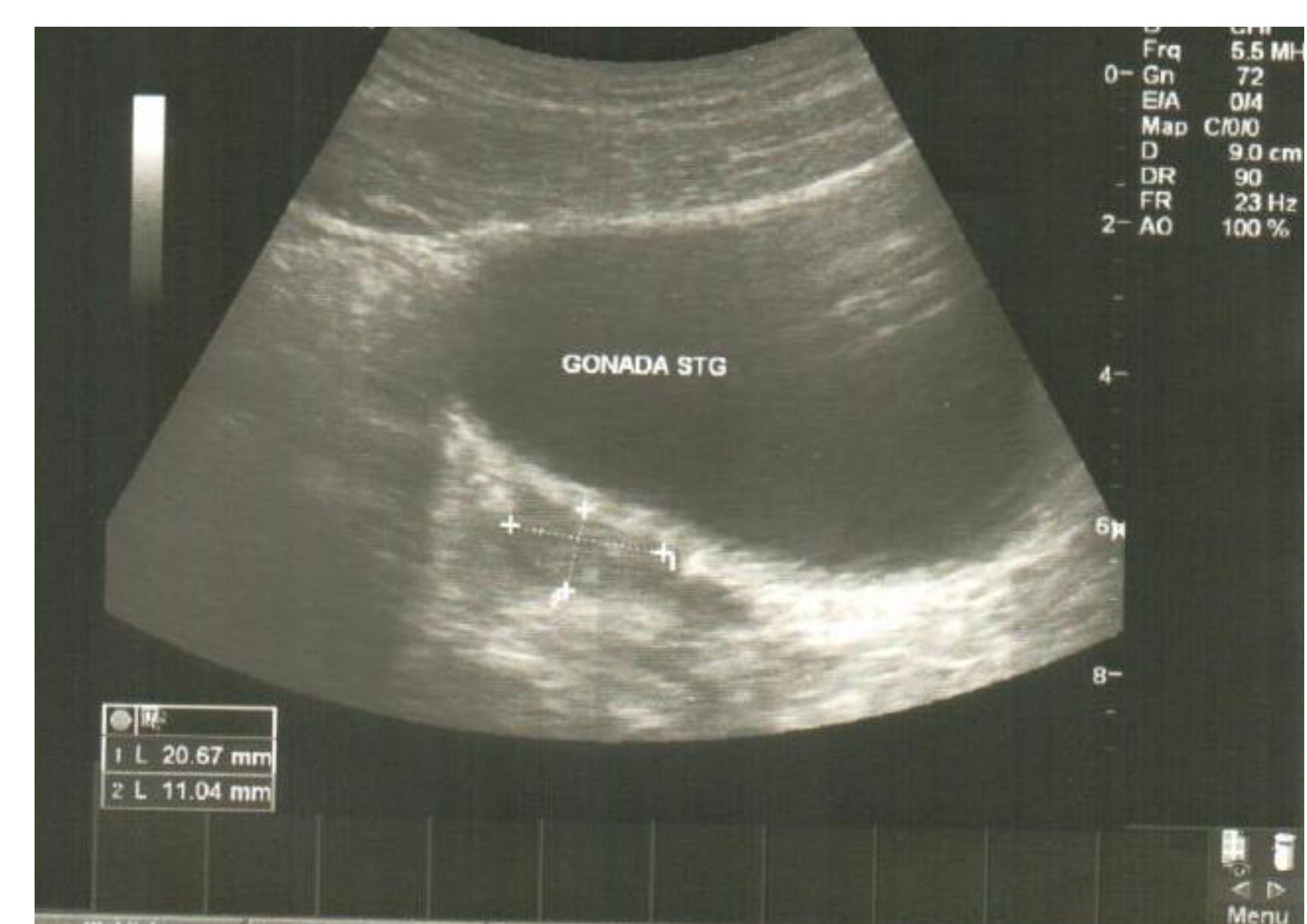

2.Left ovary

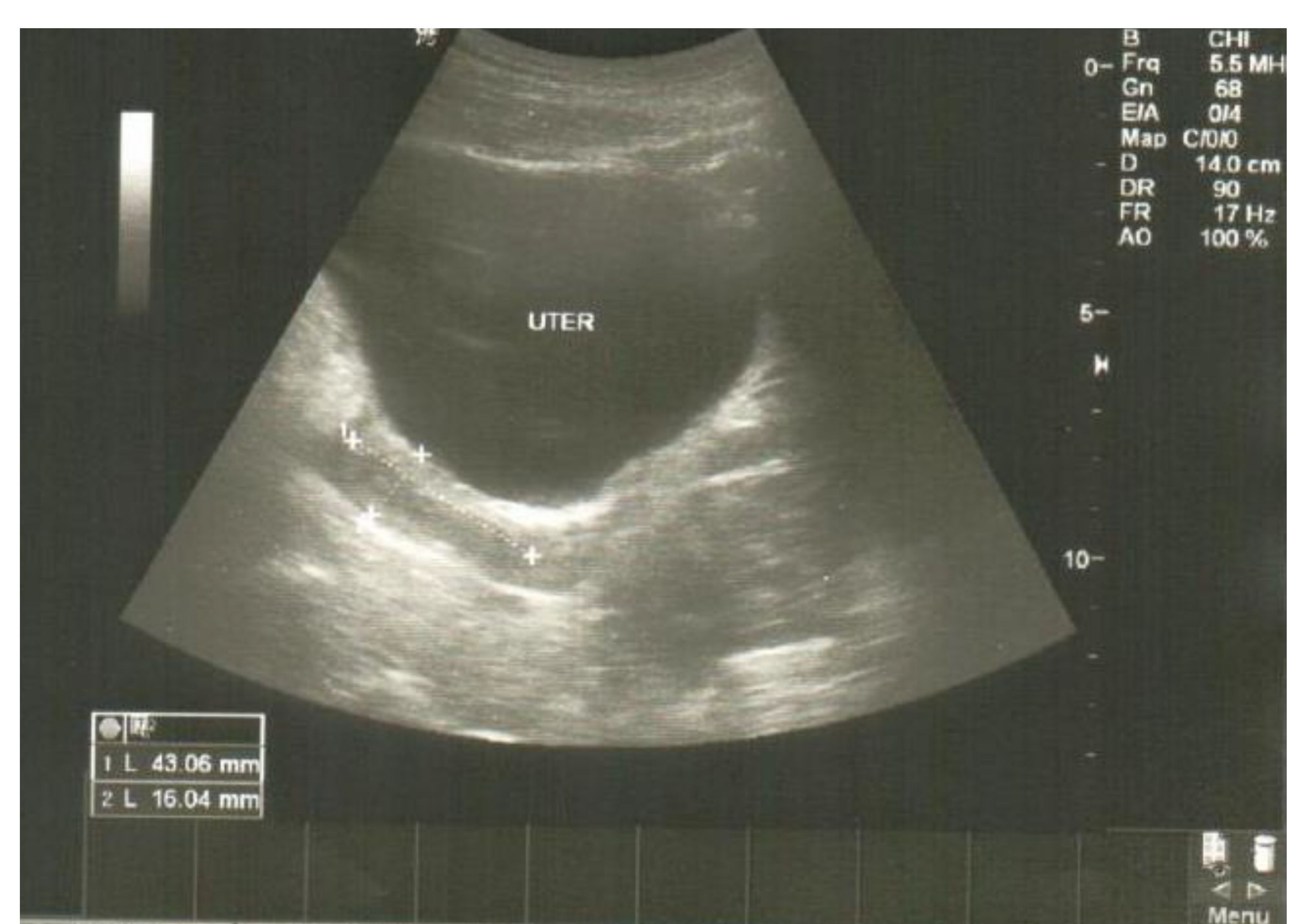

3.Uterus

Karyotype analysis showed the presence of a translocation $t(2 ; 4)$ $(2 p t e r \rightarrow p 13 ?:: 4 q$ ter $)$ in all studied metaphases with no other number or structure chromosome abnormalities detectable by G-banding. FISH-whole CR painting will be performed for CR 2 and 4 . DNA sequencing and aCGH will also be performed for changes in the translocated sequence knowing that on the short arm of CR 2 is the region where both $\mathrm{FSH}$ and $\mathrm{LH}$ receptor gene and encoded.

No genetic testing was performed to the parents or other relatives.

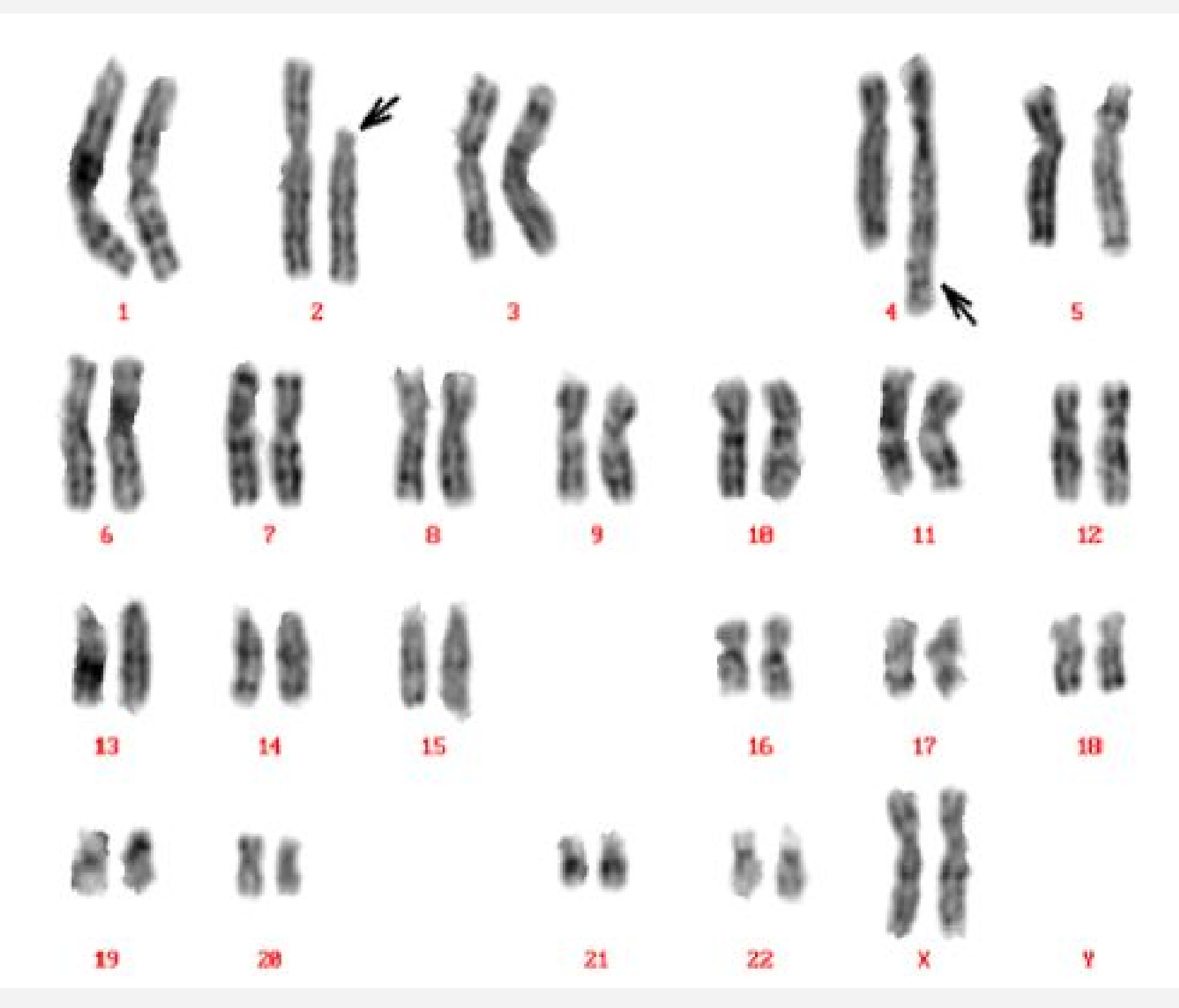

Conclusion: Genetic causes occupy the first place in the etiology of premature/primary ovarian failure (POF). Not only abnormalities of the sexual CRs but also of the autosomal ones can lead to POF. 